\title{
Enzymatic activity and gene expression of diacylglycerol kinase isozymes in developing retina of rats
}

\author{
Sakura Sato ${ }^{1,2}$, Yasukazu Hozumi ${ }^{1}$, Sachiko Saino-Saito ${ }^{1}$, Hidetoshi Yamashita ${ }^{2}$, and Kaoru Goto, ${ }^{1, *}$ \\ ${ }^{1}$ Department of Anatomy and Cell Biology, ${ }^{2}$ Department of Ophthalmology, Yamagata University School of Medicine, Yamagata \\ 990-9585, Japan
}

(Received 20 July 2011; and accepted 10 August 2011)

\begin{abstract}
Photoreceptors contain highly specialized structures for phototransduction, which is mediated by rhodopsins and heterotrimeric G-proteins. The signal is transmitted through the cGMP cascade, which controls cGMP-gated cation channels in mammals, while in flies it is operated by phosphoinositide (PI) cascade through a second messenger diacylglycerol (DG), which engenders the opening of $\mathrm{Ca}^{2+}$ channels. Recent studies suggest that PI-related signaling cascade is also involved in the phototransduction in mammalian retina. This study examined whether one PI-related enzyme, diacylglycerol kinase (DGK), which is regarded as a regulator of the DG signal through its metabolism, is expressed in mammalian retina. Enzymatic assay, Northern blot and RT-PCR analyses, and in situ hybridization histochemistry were performed to assess the expression profile of DGK isozymes and their cellular localization. In rat retina DGKe, DGK $\zeta$, and DGK1 are the dominant species with distinct patterns of expression. At the cellular level, DGKe is the only one detected intensely in the photoreceptor layer, although DGK1 and DGK $\zeta$ are observed in bipolar and ganglion cell layers. These results suggest that each DGK isozyme plays a different role in the signal transduction in distinct cell types and that DGKe is a candidate involved in the photoreceptor PI signaling machinery.
\end{abstract}

Signal transduction in retinal cells is initiated by the absorption of light by photopigments in the outer segment of the photoreceptor cells. Phototransduction in mammalian retinal photoreceptor cells involves a cyclic guanosine monophosphate (cGMP) signaling cascade that controls cGMP-gated cation channels, through which photoreceptors release glutamate continuously in the dark or attenuate its release when stimulated by light $(1,7)$. The photosignal is conveyed via bipolar cells to ganglion cells, the axons of which extend to the lateral geniculate nucleus through the optic nerve and tract.

Address correspondence to: Kaoru Goto, M.D., Ph.D. Department of Anatomy and Cell Biology, Yamagata University School of Medicine Iida-Nishi 2-2-2, Yamagata 990-9585, Japan Tel: +81-23-628-5207, Fax: +81-23-628-5210 E-mail: kgoto@med.id.yamagata-u.ac.jp
In contrast, phototransduction in flies is operated by phosphoinositide (PI) signaling (14, 39). Triggering of the cell surface receptors, such as G-proteincoupled receptors, initiates the PI cycle by activating phospholipase C (PLC), resulting in the hydrolysis of phosphatidylinositol 4,5-bisphosphate $\left(\mathrm{PIP}_{2}\right)$ into two second messengers: diacylglycerol (DG) and inositol 1,4,5-trisphosphate $\left(\mathrm{IP}_{3}\right)$ (27). In fact, DG serves as a second messenger that modulates the activity of DG-sensitive molecules, whereas $\mathrm{IP}_{3}$ mobilizes $\mathrm{Ca}^{2+}$ from the endoplasmic reticulum (23). It has been revealed that while the signal cascades in photoreceptor cells of vertebrates and flies are both initiated by activation of related rhodopsins and engagement of heterotrimeric G-proteins, there exist notable differences: Light stimulation of the rhodopsins in rods and cones of mammals increases the activity of a cGMP phosphodiesterase, resulting in closure of the cGMP-gated channels, while the cas- 
cade in fly photoreceptors is operated through activation of PLC $\beta$ and opening light-sensitive channels (transient receptor potential (TRP) and TRP-like (TRPL)) (14, 37, 39).

The importance of PI signaling in the fly retina is suggested by findings related to various Drosophila mutants of the PI cascade components $(14,26,37)$. A defect in Drosophila-PLC enzyme results in a mutant called norpA, the photoreceptors of which fail to give any electrical response to light $(3,16$, 24). Furthermore, Drosophila retinal degeneration A $(r d g A)$ mutant, which lacks eye-specific DGK activity, has photoreceptor cells that differentiate normally but degenerate rapidly after eclosion $(16,18,22)$. Analyses of other Drosophila retinal degeneration mutants, $c d s$ and retinal degeneration B ( $r d g B)$, have also revealed that their degeneration is closely related to PI synthesis and its supply through subrhabdomeric cisternae (SRC) to the rhabdomere. CDP-DG synthase (CDS), encoded by $c d s$ gene, catalyzes phosphatidic acid (PA) by converting it to CDP-DG. It plays a role in photoreceptor function and maintenance by regulating the amount of PI in the photoreceptive membrane (38). The PI-transfer protein encoded by the $r d g B$ gene is localized to the SRC membranes and adjacent photoreceptive membranes, suggesting that the $r d g B$ protein controls the PI concentration in the photoreceptive membrane by transporting PI from the SRC to the rhabdomere (31).

In this regard, it has been suggested that PI signaling pathway exists in the rod outer segment (ROS) of vertebrates $(8,25)$. The existence of a $\mathrm{PIP}_{2}$-specific PLC in vertebrate retinas and ROS is demonstrated by enzyme characterization and immunocytochemical localization. Furthermore, recent studies have revealed a small subset of retinal ganglion cells, which are intrinsically photosensitive (ipRGCs) and which function in photoentrainment of circadian rhythm and in light-induced pupillary constriction (2). Moreover, the phototransduction cascade in the ipRGCs shares striking similarities to that in fly photoreceptors, suggesting that the phototransduction cascades in fly photoreceptors and mammalian ipRGCs originate from common machinery.

Based on this evidence, it can be readily inferred that PI signaling is involved in signal transduction in mammalian retina, although the detailed functional aspects remain undetermined. In this regard, we and others have isolated and characterized several DGK isozymes that play important roles in cellular PI signal transduction $(13,19,28,34)$. It is particularly interesting that most of the isozymes show abundant expression in distinct patterns in the brain. We have described a unique expression pattern of each isozyme, suggesting the importance of this enzyme family in neuronal function (13). Nevertheless, little is known about the nature and the morphological aspects of DGKs in the retina, which is also of neuroectodermal origin. Therefore, we aimed in this study at examining the enzymatic activity and the expression pattern of mRNA using Northern blot and in situ hybridization analyses in the developing retina of rat to define how the different DGK isozymes are expressed.

\section{MATERIALS AND METHODS}

Animals. Developing and seven-week-old male Wistar rats (CLEA Japan Inc., Tokyo, Japan) were examined throughout this study. The day of birth was designated as P0. The rats were housed under freely ranging circumstances in our animal facilities under normal lighting conditions (lights on $08: 00-20: 00$ ) and were allowed ad libitum access to normal rodent chow and water. The eyes were dissected under light conditions (12:00-15:00). All animals were treated according to the statement for the 'Principles of laboratory animal care' (NIH publication no. 8523, revised 1985). Guidelines for the care and use of laboratory animals of the Yamagata University School of Medicine were also followed.

Measurement of DGK enzymatic activity. Whole eyeballs were used for the DGK assay. Samples were lysed in a buffer containing $50 \mathrm{mM}$ Tris-HCl (pH 7.4), $0.25 \mathrm{M}$ sucrose, $1 \mathrm{mM}$ EDTA, 4 mM EGTA (pH 8.0), 1 mM DTT, 1 mM PMSF, and protease inhibitor cocktail (Roche Products, Indianapolis, IN) and they were sonicated. After removing cell debris by low-speed centrifugation $(550 \times g$ for $10 \mathrm{~min}$ ), total lysate was used to measure the DGK activity by the octylglucoside mixed micelle assay as described (17). Briefly, an aliquot of $10 \mu \mathrm{L}$ of the supernatant was added to a reaction mixture $(50 \mu \mathrm{L}$ total) containing either $1 \mathrm{mM}$ 1,2-dioleoylglycerolsn-glycerol (18:1/18 : 1 DG; Sigma, St. Louis, MO) or 1-stearoyl-2-arachidonoyl-sn-glycerol (18:0/ 20:4 DG; Sigma), 6 mM L- $\alpha$-phosphatidyl-Lserine, $50 \mathrm{mM}$ MOPS, $1 \mathrm{mM}$ DTT, $100 \mathrm{mM} \mathrm{NaCl}$, $20 \mathrm{mM} \mathrm{NaF}, 1 \mathrm{mM}$ EGTA, $50 \mathrm{mM}$ octylglucoside, and $10 \mathrm{mM} \mathrm{MgCl}_{2}$ in the presence of $1 \mathrm{mM}$ $\left[\gamma-{ }^{32} \mathrm{P}\right]$ ATP (ICN Biomedicals Inc., Costa Mesa, CA). The reaction was initiated by adding the sample. Then the mixture was incubated for $5 \mathrm{~min}$ at $30^{\circ} \mathrm{C}$. Subsequently, $\left[{ }^{32} \mathrm{P}\right]$ phosphatidic acid generat- 
ed by endogenous DGK was separated using thinlayer chromatography and was quantified using liquid scintillation. To assess significance, KruskalWallis test was performed.

Northern blotting and RT-PCR. To prevent crosshybridization among isozymes in Northern blot analysis, each probe was derived from a specific region of the cloned rat DGK $\alpha$ (9), DGK $\beta$ (10), DGK $\gamma$ (11), DGK $\varepsilon$ (21), DGK $\zeta$ (12), and DGK1 (17). The probe sequence region for each isozyme was described previously $(29,35)$. Total RNAs were extracted from whole eyeball, retina, and brain (positive control) of adult rat using acid guanidinium thiocyanate/phenol/chloroform extraction (TRIzol; GIBCO BRL, Bethesda, MD). Each of the total RNA samples $(20 \mu \mathrm{g} / \mathrm{lane})$ was denatured with formamide and size-separated using formalin/agarose gel electrophoresis. The RNAs were transferred and fixed to a nylon membrane (Hybond-N; Amersham Pharmacia Biotech Inc., Buckinghamshire, UK) and hybridized with the $\left[\alpha-{ }^{32} \mathrm{P}\right] \mathrm{dATP}$-labeled cDNA probe for each DGK isozyme. For RT-PCR analysis, total RNA in developing retina was reverse transcribed, followed by PCR using specific primers as described previously (20).

In situ hybridization histochemistry. Eyeballs of adult seven-week-old male rats were cut into $20-\mu \mathrm{m}$ thick sections. Then the sections were mounted onto silane-coated glass slides. After fixation in $4 \%$ paraformaldehyde in $0.1 \mathrm{M} \mathrm{PB}(\mathrm{pH} \mathrm{7.4)}$ for $10 \mathrm{~min}$ at $4^{\circ} \mathrm{C}$ they were treated with $0.1 \mathrm{M}$ triethanolamine containing $0.25 \%$ acetic anhydride for $10 \mathrm{~min}$, dehydrated in a graded ethanol series (70-100\%), and air-dried as described $(29,35)$. Prehybridization was performed in a buffer containing $50 \%$ deionized formamide, $10 \%$ dextran sulfate, $300 \mathrm{mM} \mathrm{NaCl}, 8 \mathrm{mM}$ Tris-HCl (pH 7.4), 0.8 mM EDTA, 1× Denhardt's solution, and $200 \mu \mathrm{g} / \mathrm{mL}$ tRNA. The sections were subsequently hybridized in the same buffer supplemented with $\left[\alpha-{ }^{33} \mathrm{P}\right] \mathrm{dUTP}$-labeled cRNA probe overnight at $55^{\circ} \mathrm{C}$ in a moist chamber. After hybridization, sections were washed in a buffer containing $50 \%$ formamide, $300 \mathrm{mM} \mathrm{NaCl}, 0.1 \%$ sarcosyl, $10 \mathrm{mM}$ 2-mercaptoethanol at $65^{\circ} \mathrm{C}$ for $60 \mathrm{~min}$, treated with ribonuclease-A $(30 \mu \mathrm{g} / \mathrm{mL})$ at $37^{\circ} \mathrm{C}$ for $30 \mathrm{~min}$, washed in $2 \times \mathrm{SSC} / 0.1 \%$ sarcosyl $/ 10 \mathrm{mM}$ 2-mercaptoethanol at $65^{\circ} \mathrm{C}$ for $60 \mathrm{~min}$, dehydrated through an ethanol/300 $\mathrm{mM}$ ammonium acetate series $(70-100 \%)$, and exposed to Hyperfilm $\beta$ Max (Amersham Pharmacia Biotech Inc., Buckinghamshire, UK) for 7 days. Some sections were pro- cessed for liquid emulsion autoradiography using NTB-2 emulsion (Eastman Kodak Co., Rochester, NY), developed after 2 weeks, counterstained with hematoxylin, and examined using both bright-field and dark-field microscopy.

\section{RESULTS}

\section{DGK activity in the developing eye}

We first examined the total enzymatic activity of DGK in the eye. Reportedly DGK isozymes show different enzymological properties, such as substrate specificity. Of DGKs, DGKe specifically phosphorylates arachidonoyl-containing DG (1-stearoyl-2-arachidonoyl-sn-glycerol), whereas the other isozymes show no substrate specificity (32). Therefore an octylglucoside mixed-micelle assay was used to evaluate substrate specificity toward dioleoyl-sn-glycerol (18:1/18:1 DG) and 1-stearoyl-2-arachidonoyl-snglycerol (18:0/20:4 DG). As shown in Fig. 1, DGK activity was detected clearly in the eye of all developing stages examined. The overall activity in the eye was roughly estimated as $1 / 20$ of that in the brain (20) where DGKs are expressed abundantly (13). In the postnatal period, the activity was transiently elevated in early postnatal days (P3-P7) about two-fold compared with that at P0. Thereafter, the activity decreased gradually to the level of about half of that at P0. The activities toward $18: 1 / 18: 1$ DG and 18:0/20:4 DG during the postnatal period were almost comparable. Collectively, the results suggest that in the eye the total DGK activity is highest in early postnatal days and that it does not exhibit predominant substrate specificity as a whole.

\section{Expression profile of DGK isozymes}

To date, six DGK isozymes have been cloned from rat tissues. We performed Northern blot analysis to examine the expression profile of the isozymes in the retina at the mRNA level. We used the whole eyeball, including the cornea, lens, sclera, ciliary and vitreous bodies, and the retinal layers extracted from the eyeball. As portrayed in Fig. 2, all isozymes were detected in the brain at various intensities. However, in adult retina, hybridization signals were detected intensely for DGK1 and DGKe, moderately for $\mathrm{DGK} \zeta$, and weakly for DGK $\alpha$ and DGK $\beta$. DGK $\gamma$ mRNA was not detected in the retina or eyeball. The signal intensities for the detectable DGK isozymes were generally higher in the extracted retinal layer than in the whole eyeball, showing that DGKs are expressed abundantly in neural retina, except for DGK $\alpha$, the expression of which was 

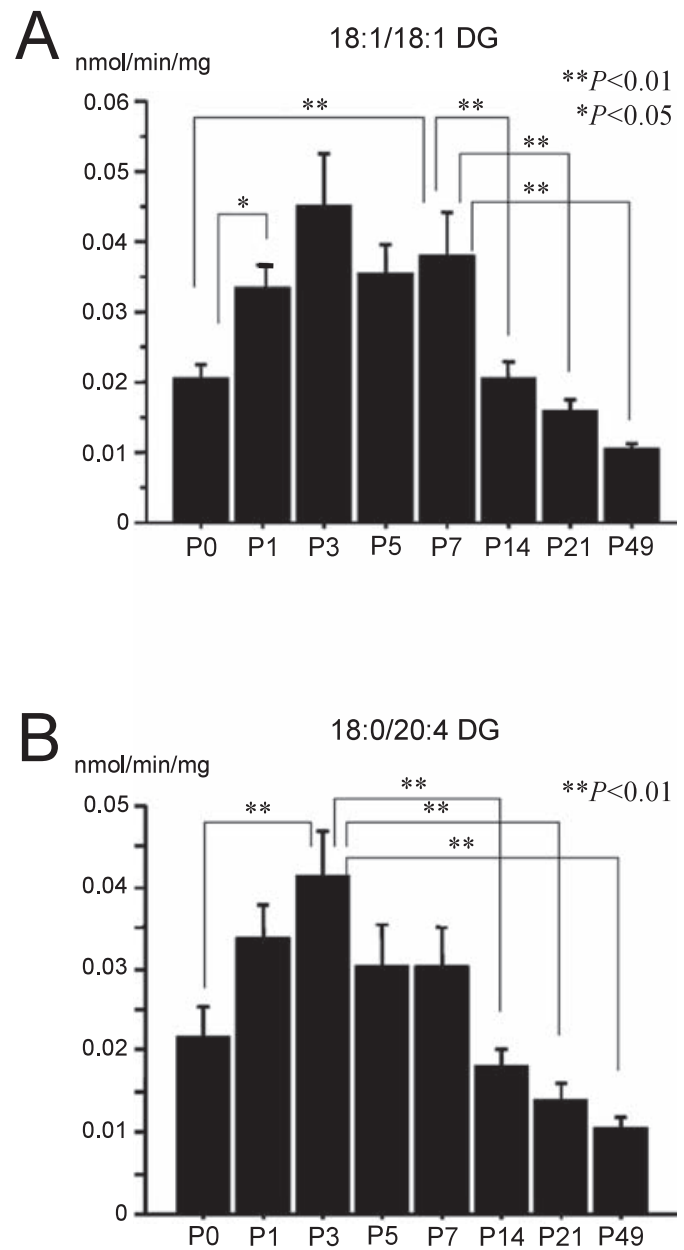

Fig. 1 DGK activities in postnatal developing eye. Homogenates of the whole eyeballs from postnatal day $(P) 0,1,3$, $5,7,14,21$, and 49 were assayed for DGK activity toward a single DG species in the octylglucoside mixed-micelle assay as described in Materials and Methods. DGK activities toward 1,2-dioleoyl-sn-glycerol (18:1/18:1 DG) (A) and 1-stearoyl-2-arachidonoyl-sn-glycerol (18:0/20:4 DG) (B) in the presence of $0.1 \mathrm{mM} \mathrm{Ca}^{2+}$. The results are expressed in $\mathrm{nmol}$ PA formed/min per $\mathrm{mg}$ of protein. Each value is the mean of triplicate assays \pm SD. Similar results were obtained in three independent experiments. Kruskal-Wallis test, ${ }^{*} P<0.05 ;{ }^{* *} P<0.01$.

lower in the extracted retina than that in the whole eyeball. These data show that DGKe, DGK $\zeta$, and DGK 1 are the major species in the retina.

During the postnatal period, the retina becomes exposed to light, although the eyelids do not open until postnatal day 14 in rats. The enzymatic activity was shown to be highest in early postnatal days (Fig. 1). Therefore, we roughly estimated temporal expression patterns of mRNA for major DGK isozymes in the developing retina by RT-PCR (Fig. 3). Expression signals for $\mathrm{DGK} \varepsilon$ and $\mathrm{DGK} \zeta$ increased during the first week after birth and reached the plateau level after P14, whereas those for DGK1 increased transiently in early postnatal days and decreased after P14.

\section{Cellular expression of DGK isozymes}

To investigate the cellular expression of DGK isozymes, we examined mRNA localization using in situ hybridization histochemistry. In adult retina, the expression signals were detected clearly for DGKe, DGK $\zeta$, and DGKı (Fig. 4). The mRNA signals for DGK $\zeta$ were detected intensely in the inner nuclear layer (INL) and ganglion cell layer (GCL) (Fig. 4N). The signals for DGKi were predominant in the INL and moderate in the GCL (Fig. 4O). Both signals were below detection levels in the inner segment (IS) and outer nuclear layer (ONL), where photoreceptor cells are located. In contrast to the expression patterns observed for DGK $\zeta$ and DGKl, the signals for DGK $\varepsilon$ were detected intensely in the IS, moderately in the ONL and faintly in the GCL (Fig. 4M), suggesting the expression of this isozyme in photoreceptor cells.

In developing retina, the signals for all of those DGKs were first detected weakly in the inner blast cell layer at P0. Thereafter, the signals for DGK $\zeta$ and DGKı increased gradually in the INL and GCL, whereas those for DGKe were confined to the IS and ONL. Adult expression patterns were observed for all of those DGKs at P14 when the layers were differentiated distinctly. Control experiments using labeled sense strand RNA probes gave no detectable signals in the sections, confirming the specificity of the hybridization signals in this study (data not shown).

\section{DISCUSSION}

This study revealed for the first time the expression profile of DGKs in mammalian retina, i.e. the enzymatic activity and characteristic mRNA expression patterns of DGK isozymes. First, we show clearly that DGKe mRNA is detected intensely in the photoreceptor layer (IS and ONL), whereas those for DGK $\zeta$ and DGKi are below detection levels in the same region. This finding suggests that DGKe is the only isozyme that is intensely expressed in photoreceptor cells. Combined with a previous study, showing the localization of PLC in the outer segment of mammalian retinal photoreceptor cells (25), this study further supports the existence of PI signaling machinery in photoreceptor cells, such as the production and attenuation of the second messenger DG. 


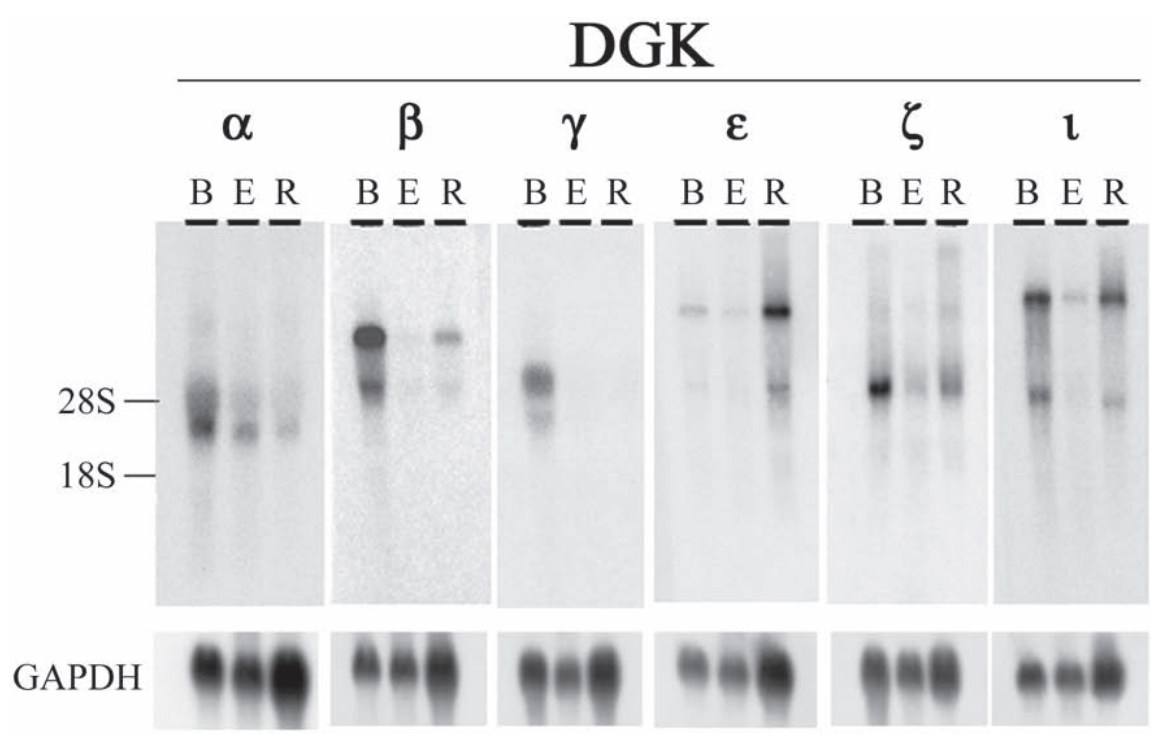

Fig. 2 Northern blot analysis of the DGK isozymes in the retina. Total RNA (20 $\mu$ g per lane) from the retina (R), whole eyeball $(E)$, and brain ( $B$, as a positive control) was analyzed. After electrophoresis and transfer of the samples, the filter was hybridized to each of ${ }^{32} \mathrm{P}$-labeled cDNA probes for rat DGKa, $-\beta,-\gamma,-\varepsilon,-\zeta$, and $-\iota$. GAPDH probe was used as a control on the same filter.

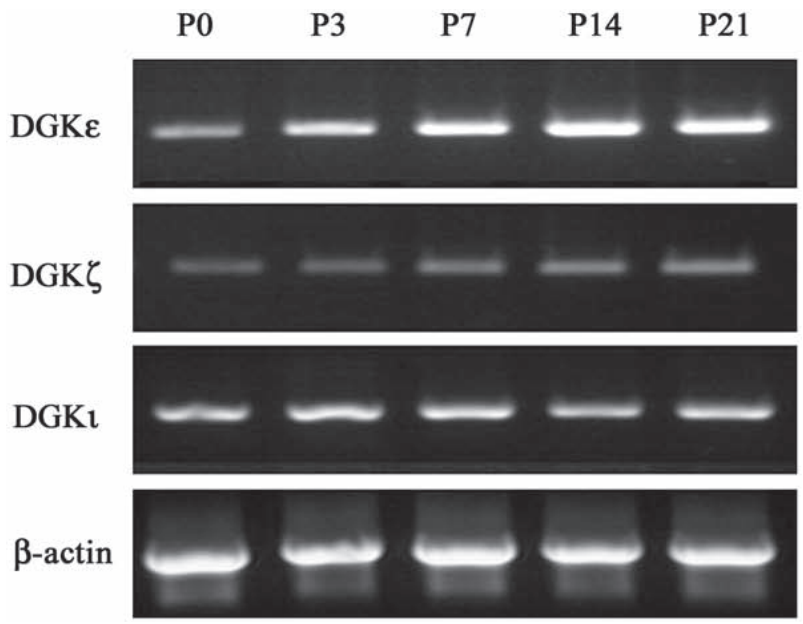

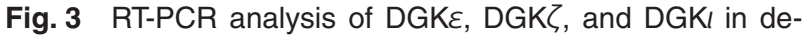
veloping retina. In RT-PCR analysis of developing retinas from postnatal day $(P) 0,3,7,14$, and 21 , bands for DGK isozymes were amplified using specific primer for each isozyme and electrophoresed. $\beta$-actin primer was also used as a control. PCR was performed for 35 cycles. A similar tendency was obtained in PCR for 30 and 32 cycles.

As noted in the Introduction, mammalian phototransduction system is mainly operated in cGMPgated channels, which remain open in the dark and quickly close in response to the light, leading to hyperpolarization $(1,7)$. Then, what is the functional role of DGKe in photoreceptor cells? Clues to answer that question might be suggested by two points: one is a specialized structure of these cells and the other is a characteristic of DGKe. The outer segment is a site of the initial step of photoreception in photoreceptor cells. It comprises hundreds of stacked rhodopsin-laden membranous disks enveloped by the rod's plasma membrane. The old disks in the distal part of the segment are engulfed by pigment epithelial cells to be replaced by new ones, which are added to the proximal part. It is worth noting that the outer segment membrane is characteristically enriched in polyunsaturated fatty acids, such as arachidonic and docosahexaenoic acids (30). Although the reason of this enrichment remains enigmatic, it is speculated that phospholipids with polyunsaturated fatty acids stabilize the membrane structure of the outer segment. Considering that DGKe catalyzes arachidonoyl-DG specifically, this isozyme is probably engaged in the PI cycle distinctly (36) because PI has a characteristic fatty acid composition, 1-stearoyl-2-arachidonoyl species (15). Taken together, one hypothesis might be that DGKe participates in the turnover of the disk membrane in the outer segment.

As for $\mathrm{DGK} \zeta$ and $\mathrm{DGK} 1, r d g A$ gene product in Drosophila, designated as DGK2, is identified as an eye-specific DGK characterized by ankyrin repeats (22). Molecular cloning of mammalian DGKs made it possible to compare the structural features, which reveals that class IV DGK-DGK $\zeta(5,12)$ and DGK $1(6,17)$ - share a similar structural motif: an- 


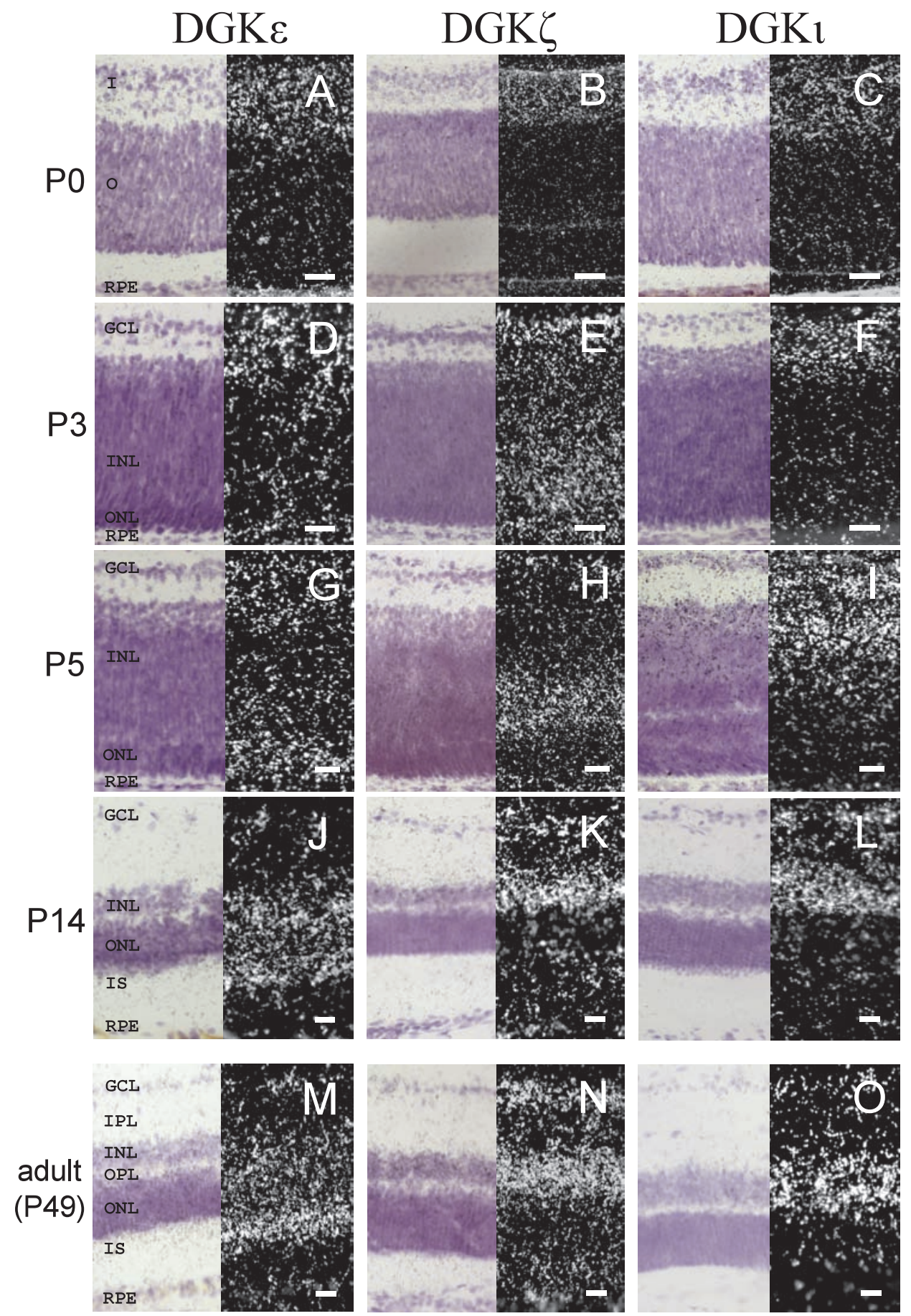

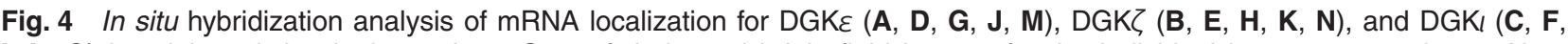
$\mathbf{I}, \mathbf{L}, \mathbf{O})$ in adult and developing retinas. Sets of dark- and bright-field images for the individual isozymes are shown. Note the distinct mRNA expression patterns of the isozymes in the retina. In the adult retina, the mRNA signals for DGK $\varepsilon$ are intensely detected in the IS, moderately in the ONL and faintly in the GCL (M). On the other hand, the signals for DGK $\zeta$ are detected intensely in the INL and GCL $(\mathbf{N})$ while the signals for DGKI are predominant in the INL and moderate in the GCL $(\mathbf{O})$, both of which signals are below detection levels in the IS and ONL. Note in developing retina that the signals for all of those DGKs are first detected weakly in the inner blast cell layer at P0 (A, B, C). Thereafter, the signals for DGK DGK l gradually increase in the INL and GCL, while those for DGKE in the IS and ONL. Adult expression pattern is observed for all of those DGKs at P14 when the layers are distinctly differentiated. I, inner blast cell layer; O, outer blast cell layer; GCL, ganglion cell layer; IPL, inner plexiform layer; INL, inner nuclear layer; OPL, outer plexiform layer; ONL, outer nuclear layer; IS, inner segment; RPE, retinal pigment epithelium. Bars $20 \mu \mathrm{m}$. 
kyrin repeats. Recent studies show that a small subset of retinal ganglion cells, ipRGCs, function in photoentrainment of circadian rhythm and in lightinduced pupillary constriction (2). Gene expression of DGK $\zeta$ and DGKı in the GCL as well as INL, as revealed in the present study, may suggest that these isozymes are involved in the phototransduction cascade in the ipRGCs, which share striking similarities to the cascade in fly photoreceptors.

In terms of the enzymatic activity, the overall DGK activity in the eye is revealed to be highest in early postnatal days and decrease thereafter. This result might suggest that DGK activity plays a particular role for structural and functional development of retinal layers. However, the developmental change in the total enzymatic activity is not correlated with that in the mRNA expression levels of DGKs. This apparent discrepancy remains unclear, although it might be that the relative amount of DGK protein is decreased at the adult stage (P49) or that distinct regulatory mechanisms of the enzymatic activity exist in developing stages. Further study is needed to elucidate this point.

Retinal degeneration in various Drosophila mutants of the PI signaling components (37) suggests a possible involvement of mammalian DGKs in retinal diseases. Considering the tissue expression pattern, DGK 1 is regarded as the most likely candidate for a human orthologue of $r d g A$ (6). However, no apparent disease-associated mutations for human DGKı have been identified in inherited retinopathy (autosomal dominant retinitis pigmentosa, adRP) (4). However, a search for disease gene linkage reveals that human $\mathrm{DGK} \varepsilon$ gene maps within the adRP disease gene interval, although no mutation in the coding sequence of human DGKe from two patients is identified at the moment (33). Considering that photoreceptor cells are primary sites of retinal degeneration, it is reasonable that the defect of DGKe might cause dysregulation of the DG metabolism, i.e., accumulation of DG and/or deficiency of PA, in these cells. Further studies are necessary to dissect the functional role of DGKe and the causative link to retinopathy at the protein level using specific antibodies.

\section{Acknowledgements}

This work was supported by Grant-in-Aid from The Ministry of Education, Culture, Sports, Science and Technology (MEXT) of Japan (K.G.)

\section{REFERENCES}

1. Arshavsky VY, Lamb TD and Pugh EN, Jr. (2002) G proteins and phototransduction. Annu Rev Physiol 64, 153-187.

2. Berson DM (2007) Phototransduction in ganglion-cell photoreceptors. Pflugers Arch 454, 849-855.

3. Bloomquist BT, Shortridge RD, Schneuwly S, Perdew M, Montell C, Steller H, Rubin G and Pak WL (1988) Isolation of a putative phospholipase C gene of Drosophila, norpA, and its role in phototransduction. Cell 54, 723-733.

4. Bowne SJ, Sullivan LS, Ding L, Traer E, Prescott SM, Birch DG, Kennan A, Humphries P and Daiger SP (2000) Evaluation of human diacylglycerol kinase 1, DGKI, a homolog of Drosophila $r d g A$, in inherited retinopathy mapping to $7 \mathrm{q}$. Mol Vis 6, 6-9.

5. Bunting M, Tang W, Zimmerman GA, McIntyre TM and Prescott SM (1996) Molecular cloning and characterization of a novel human diacylglycerol kinase $\zeta$. J Biol Chem 271, 10230-10236.

6. Ding L, Traer E, McIntyre TM, Zimmerman GA and Prescott SM (1998) The cloning and characterization of a novel human diacylglycerol kinase, DGK1. J Biol Chem 273, 3274632752.

7. Dowling JE (1987) The Retina: An Approachable Part of the Brain. Belknap Press of Harvard University Press, Cambridge, Mass.

8. Gehm BD and McConnell DG (1990) Phosphoinositide synthesis in bovine rod outer segments. Biochemistry 29, 54425446.

9. Goto K, Watanabe M, Kondo H, Yuasa H, Sakane F and Kanoh H (1992) Gene cloning, sequence, expression and in situ localization of $80 \mathrm{kDa}$ diacylglycerol kinase specific to oligodendrocyte of rat brain. Brain Res Mol Brain Res 16, 75-87.

10. Goto K and Kondo H (1993) Molecular cloning and expression of a $90-\mathrm{kDa}$ diacylglycerol kinase that predominantly localizes in neurons. Proc Natl Acad Sci USA 90, 75987602.

11. Goto K, Funayama M and Kondo H (1994) Cloning and expression of a cytoskeleton-associated diacylglycerol kinase that is dominantly expressed in cerebellum. Proc Natl Acad Sci USA 91, 13042-13046.

12. Goto K and Kondo H (1996) A 104-kDa diacylglycerol kinase containing ankyrin-like repeats localizes in the cell nucleus. Proc Natl Acad Sci USA 93, 11196-11201.

13. Goto K, Hozumi Y, Nakano T, Saino-Saito S and Kondo H (2007) Cell biology and pathophysiology of the diacylglycerol kinase family: morphological aspects in tissues and organs. Int Rev Cytol 264, 25-63.

14. Hardie RC (2003) Regulation of TRP channels via lipid second messengers. Annu Rev Physiol 65, 735-759.

15. Holub BJ and Kuksis A (1978) Metabolism of molecular species of diacylglycerophospholipids. Adv Lipid Res 16, 1-125.

16. Hotta Y and Benzer S (1970) Genetic dissection of the Drosophila nervous system by means of mosaics. Proc Natl Acad Sci USA 67, 1156-1163.

17. Ito T, Hozumi Y, Sakane F, Saino-Saito S, Kanoh H, Aoyagi M, Kondo H and Goto K (2004) Cloning and characterization of diacylglycerol kinase 1 splice variants in rat brain. $J$ Biol Chem 279, 23317-23326.

18. Johnson MA, Frayer KL and Stark WS (1982) Characteristics of Rdga - mutants with retinal degeneration in Drosophila. J Insect Physiol 28, 233-242.

19. Kanoh H, Yamada K and Sakane F (1990) Diacylglycerol ki- 
nase: a key modulator of signal transduction? Trends Biochem Sci 15, 47-50.

20. Katagiri Y, Ito T, Saino-Saito S, Hozumi Y, Suwabe A, Otake $\mathrm{K}$, Sata M, Kondo H, Sakane F, Kanoh H, Kubota I and Goto K (2005) Expression and localization of diacylglycerol kinase isozymes and enzymatic features in rat lung. Am $J$ Physiol Lung Cell Mol Physiol 288, L1171-1178.

21. Kohyama-Koganeya A, Watanabe M and Hotta Y (1997) Molecular cloning of a diacylglycerol kinase isozyme predominantly expressed in rat retina. FEBS Lett 409, 258-264.

22. Masai I, Okazaki A, Hosoya T and Hotta Y (1993) Drosophila retinal degeneration A gene encodes an eye-specific diacylglycerol kinase with cysteine-rich zinc-finger motifs and ankyrin repeats. Proc Natl Acad Sci USA 90, 11157-11161.

23. Nishizuka Y (1992) Intracellular signaling by hydrolysis of phospholipids and activation of protein kinase C. Science 258, 607-614.

24. Pak WL, Grossfield J and Arnold KS (1970) Mutants of the visual pathway of Drosophila melanogaster. Nature 227, 518-520.

25. Peng YW, Rhee SG, Yu WP, Ho YK, Schoen T, Chader GJ and Yau KW (1997) Identification of components of a phosphoinositide signaling pathway in retinal rod outer segments. Proc Natl Acad Sci USA 94, 1995-2000.

26. Raghu P, Colley NJ, Webel R, James T, Hasan G, Danin M, Selinger Z and Hardie RC (2000) Normal phototransduction in Drosophila photoreceptors lacking an InsP(3) receptor gene. Mol Cell Neurosci 15, 429-445.

27. Rhee SG, Suh PG, Ryu SH and Lee SY (1989) Studies of inositol phospholipid-specific phospholipase C. Science 244, 546-550.

28. Sakane F, Imai S, Kai M, Yasuda S and Kanoh H (2007) Diacylglycerol kinases: why so many of them? Biochim Biophys Acta 1771, 793-806.

29. Sasaki H, Hozumi Y, Hasegawa H, Ito T, Takagi M, Ogino T, Watanabe M and Goto K (2006) Gene expression and local- ization of diacylglycerol kinase isozymes in the rat spinal cord and dorsal root ganglia. Cell Tissue Res 326, 35-42.

30. Simopoulos AP and Bazán NG (2009) Omega-3 Fatty Acids, the Brain, and Retina. Karger, Basel; New York.

31. Suzuki E and Hirosawa K (1994) Immunolocalization of a Drosophila phosphatidylinositol transfer protein $(r d g B)$ in normal and $r d g A$ mutant photoreceptor cells with special reference to the subrhabdomeric cisternae. $J$ Electron Microsc (Tokyo) 43, 183-189.

32. Tang W, Bunting M, Zimmerman GA, McIntyre TM and Prescott SM (1996) Molecular cloning of a novel human diacylglycerol kinase highly selective for arachidonate-containing substrates. J Biol Chem 271, 10237-10241.

33. Tang W, Bardien S, Bhattacharya SS and Prescott SM (1999) Characterization of the human diacylglycerol kinase $\varepsilon$ gene and its assessment as a candidate for inherited retinitis pigmentosa. Gene 239, 185-192.

34. Topham MK and Epand RM (2009) Mammalian diacylglycerol kinases: molecular interactions and biological functions of selected isoforms. Biochim Biophys Acta 1790, 416-424.

35. Toya M, Hozumi Y, Ito T, Takeda M, Sakane F, Kanoh H, Saito H, Hiroi M, Kurachi H, Kondo H and Goto K (2005) Gene expression, cellular localization, and enzymatic activity of diacylglycerol kinase isozymes in rat ovary and placenta. Cell Tissue Res 320, 525-533.

36. Walsh JP, Suen R, Lemaitre RN and Glomset JA (1994) Arachidonoyl-diacylglycerol kinase from bovine testis. Purification and properties. J Biol Chem 269, 21155-21164.

37. Wang T and Montell C (2007) Phototransduction and retinal degeneration in Drosophila. Pflugers Arch 454, 821-847.

38. Wu L, Niemeyer B, Colley $\mathrm{N}$, Socolich $\mathrm{M}$ and Zuker CS (1995) Regulation of PLC-mediated signalling in vivo by CDP-diacylglycerol synthase. Nature 373, 216-222.

39. Zuker CS (1996) The biology of vision of Drosophila. Proc Natl Acad Sci USA 93, 571-576. 